http://jmscr.igmpublication.org/home/ ISSN (e)-2347-176x ISSN (p) 2455-0450

crossref DOI: https://dx.doi.org/10.18535/jmscr/v7i12.41

\title{
Evaluation of Doppler Ultrasound Study of Threatened Abortion, Missed Abortion and Anembryonic Pregnancy
}

\author{
Authors \\ Jha Vandana ${ }^{1}$, Panda Subrat ${ }^{2}$, Anindita Sinha ${ }^{3}$, Singh A Santa ${ }^{4}$ \\ ${ }^{1,2,4}$ Department of Obstetrics and Gynaecology, NEIGRIHMS \\ ${ }^{3}$ Department of Radiology and Imaging, NEIGRIHMS
}

\begin{abstract}
:
Aim: To evaluate changes in uteroplacental circulation in pregnancy complications up to 20 weeks.

Methods: 26 women with threatened abortion with a living embryo, 24 women with anembryonic pregnancy, in addition to 22 women with missed abortion were included. In all women, trans-abdominal colour Doppler ultrasound study was performed including measurement of resistance index (RI) and pulsatility index (PI) of uterine arteries. Results are analysed statisitically.

Statistics used: Unpaired t test

Result: vascular indices of missed abortion RI and PI have higher values than threatened abortion RI and PI. Difference was significant for PI with $(P$ value of $<0.001)$ and for RI with $(P$ value of $<0.01)$. In our study we found that anembryonic pregnancies having higher RI and PI than those of threatened abortion cases. Here difference is significant for RI with (P value $<0.001)$ ), but difference is not significant for PI.

Conclusion: early pregnancy complications like threatened abortion, missed abortion and anembryonic pregnancy are associated with marked changes in uteroplacental circulation. This abnormal blood flow pattern may increase the oxidative stress on the early placental tissue and subsequently impair placental development. Direct clinical implication need more research but these vascular studies helps us in understanding the pathophysiology of early pregnancy failure, helping in more rational management as well as predicting the outcome of these pregnancies.
\end{abstract}

\section{Introduction}

Man's quest to search for better endlessly leads to development of new technology every day, one of the best example of this is use of new generation of pulsed and color Doppler equipment in early pregnancy. This technology makes it possible to map uteroplacental circulation from the first weeks of gestation ${ }^{1}$. Doppler enables a close evaluation of early embryonic development and blood flow studies in embryonic and fetal vessels. These informations could play an important role in the assessment of early pregnancy failure. $^{2}$
Aim is to know the pathophysiological changes in uteroplacental circulation associated with early pregnancy complication

\section{Material and Method}

Nature of Study: Prospective study carried out for 1year

Place of study: Northeastern Indira Gandhi Reigonal Institute of Health and Medical Science. Patient having complain of bleeding per vaginum in pregnancy upto $20^{\text {th }}$ weeks were included. Provisional clinical diagnosis was made in every case. Ultrasonographic examination was done for 
every patient under the study using following ultrasound machine 1) LOGIQ P5, MODEL NO5372509 (GE ULTRASOND KOREA)2) HEWLETT PACKWARD, MODEL NO -5R5315 (M2410B ULTRASOUND SYSTEM). Cases of clinically diagnosed threatened abortion showing viable pregnancy are taken as threatened abortion group. Cases showing diagnosis of blighted ovum criteria (Transabdominally, a gestational sac greater than $20 \mathrm{~mm}$ without a yolk sac or $25 \mathrm{~mm}$ without an embryo is diagnostic

of a blighted ovum, or transvaginally mean gestational sac diameter exceeds $8 \mathrm{~mm}$ without a yolk sac or when the mean gestational sacdiameter exceeds $16 \mathrm{~mm}$ without an embryo) taken as blighted ovum group. Coventional ultrasonography showing no cardiac pulsation taken as missed abortion group. In all cases
Doppler ultrasound was performed. Measurement of RI (resistance index) and PI (pulsatility index) was done in each cases.

\section{Results}

Results are divided in two groups, (a) general characteristic (b) study parameter

Table -1 presents the general characteristic of study group .coincidentally mean parity of threatened abortion is same as anembryonic pregnancy. While parity of missed abortion is comparable to threatened abortion. mean age group of anembryonic pregnancy cases are highest in comparison to missed and threatened abortion. All three groups are comparable regarding period of gestation, so possibility of period of gestation as confounding factor regarding result of vascular indices can be ruled out.

Table 1 Characteristic of Doppler study group patients

\begin{tabular}{|l|c|c|c|}
\hline & Age(Mean)years & Gravida(mean) & POG inWeeks(Mean) \\
\hline Threatened abortion $(\mathrm{n}=18)$ & 24.8 years & 2.6 & 10.2 Weeks \\
\hline Missed abortion $(\mathrm{n}=12)$ & 26.6 years & 3.4 & 11.4 weeks \\
\hline Anembryonic pregnancy $(\mathrm{n}=16)$ & 29.4 years & 2.6 & 10.02 weeks \\
\hline
\end{tabular}

Table 2 Results of Doppler study

\begin{tabular}{|l|c|c|}
\hline Parameter Group & RI $($ mean \pm S.D $)$ & PI $($ mean \pm S.D $)$ \\
\hline THREATENED ABORTION & $0.72(0.06)$ & $\mathrm{I} .77(0.35)$ \\
\hline MISSED ABORTION & $0.8 \mathrm{I}(0.08)$ & $2.59(0.20)$ \\
\hline ANEMBRYONIC & O.91(0.04) & $2.03(0.43)$ \\
PREGNANCY & & \\
\hline
\end{tabular}

While comparing vascular indinces of threatened abortion patient with missed abortion, as shown in Table 3, we found that vascular indices (RI, PI) of missed abortion have higher values than threatened abortion. Here difference is significant for PI with $(\mathrm{P}<0.001)$ and for RI with $(\mathrm{P}<0.01)$.

Table 3 Comparisons between Doppler indices of threatened and missed abortion

\begin{tabular}{|l|c|c|}
\hline Parameter group & RI & PI \\
\hline THREATENED ABORTION & $0.72(0.06)$ & $1.77(0.35)$ \\
\hline MISSED ABORTION & $0.81(0.08)$ & $2.59(0.20)$ \\
\hline P VALUE & $\mathrm{P}<0.01$ & $\mathrm{P}<0.001$ \\
\hline
\end{tabular}

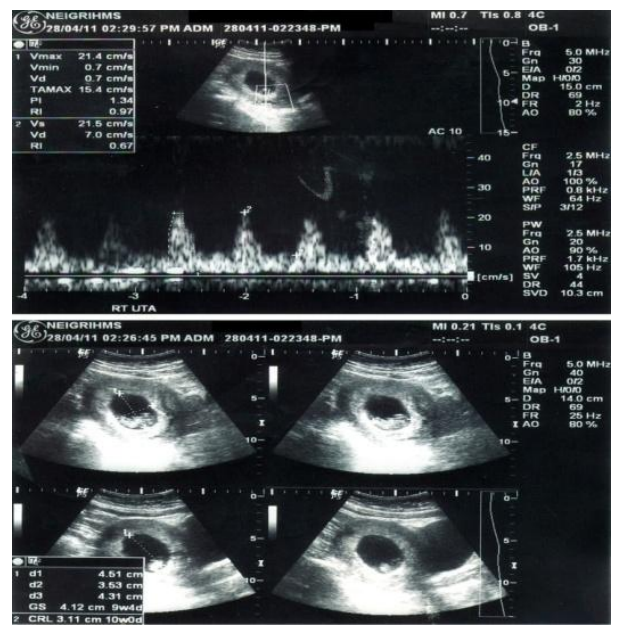

Figure: 1 Doppler study of threatened abortion showing low resistance flow 


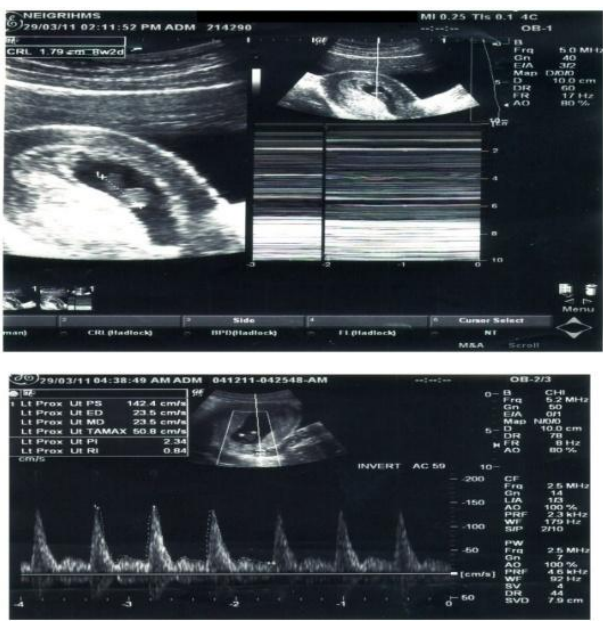

Figure: 2 Doppler study of missed abortion showing high impedance flow
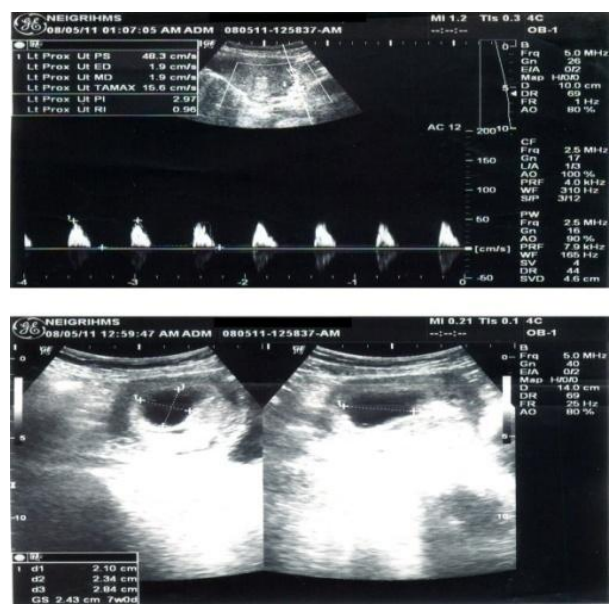

Figure 3 Doppler study of blighted ovum showing high resistance flow

In our study we found that threatened abortion having lower RI and PI than anembryonic pregnancies. Difference is significant for RI (P $<0.001$ ), but difference is not significant for PI as evident from table 4.

Table 4 Comparison of Doppler indices between threatened and Anembryonic pregnancy

\begin{tabular}{|l|c|c|}
\hline Parameter group & RI & PI \\
\hline $\begin{array}{l}\text { THREATENED } \\
\text { ABORTION }\end{array}$ & $0.72(0.06)$ & $1.77(0.35)$ \\
\hline $\begin{array}{l}\text { ANEMBRYONIC } \\
\text { PREGNANCY }\end{array}$ & $0.91(0.04)$ & $2.03(0.43)$ \\
\hline P VALUE & $\mathrm{P}<0.001$ & NOT SIGNIFICANT \\
\hline
\end{tabular}

\section{Discussion}

There are limited studies on Doppler evaluation of first trimester pregnancy, we have done Doppler study in cases of missed abortion, threatened abortion and anembryonic pregnancy.
In our study we found that threatened abortion having lower RI and PI than anembryonic pregnancies. Difference is significant for RI ( $P$ $<0.001$ ), but difference is not significant for PI. This is in agreement with Study by faiz et al. ${ }^{3}$

Study by Faiz et al concluded that Patient with threatened abortion have significantly lower S/D ratio and RI than in those with anembryonic pregnancy $(\mathrm{P}<0.01)$. They also found that patients with threatened abortion have lower figures for S/D, RI and PI compared to normal groups.

While comparing vascular indices of threatened abortion patient with missed abortion, we found that vascular indices (RI, PI) of missed abortion have higher values than threatened abortion. Here difference is significant for PI with $(\mathrm{P}<0.001)$ and for RI with $(\mathrm{P}<0.01)$. This is in agreement with below mentioned study.

ERIC et $\mathrm{al}^{4}$ concluded that mean uterine PI was significantly $(\mathrm{P}<0.01)$ higher in missed abortions compared to normal controls. As study by faiz et al shows that patients with threatened abortion have lower figures for S/D, RI and PI compared to normal groups.

\section{Conclusion}

Doppler evolution of early pregnancy is still in its infancy as compared to second and third trimester. As recent studies shows that in about two third of early pregnancy failure there is anatomical evidences of defective placentation. Our studies shows also shows that vascular indices RI, PI having significant difference in threatened abortion, anembryonic pregnancy and missed abortion. These findings is in agreement with recent studies that abnormal flow velocity waveforms in early pregnancies complicated by embryonic death are related to deficient placentation. The premature entry of maternal blood into the intervillous space disrupts the materno-embryonic interface and is probably the final mechanism causing abortion.

Direct clinical implication need more research but these vascular studies helps us in understanding 
the pathophysiology of early pregnancy failure, helping in more rational management as well as predicting as the outcome.

\section{References}

1. Martin AM, Bindra R, Curcio P, Cicero S, Nicolaides KH. Screening for preeclampsia and fetal growth restriction by uterine artery Doppler at 11-14 weeks of gestation. Ultrasound Obstet Gynecol 2001;18:583-6

2. Kurjak, Asim; Zalud, Ivica; Salihagic, Aida; Crvenkovic, Gordan; Matijevic, Ratko. Transvaginal color Doppler in assessment of abnormal early pregnancy. Journal of perinatal medicine.1991; 19(3):155-165.

3. Faiz A J, Al Waeely. Evaluation of doppler ultrasound study in first trimester threatened abortion and anembryonic pregnancy.MJBU.2005; 23(2): 5-7.

4. Jauniaux Eric, Zaidi Jamal, Jurkovic Davor, Campbell Stuart 'Hustin Jean .Pregnancy: Comparison of colour Doppler features and pathological findings in complicated early pregnancy. Hum. Reprod. 1994; 9 (12): 2432-2437. 